\title{
KOHESI SELF-ESTEEM DAN KEMAMPUAN RESILIENSI ANAK MARGINAL DALAM ROMAN PÜNKTCHEN UND ANTON
}

\author{
Saskia Nabila \\ saskia.nabila@ui.ac.id \\ Lisda Liyanti \\ lisda.liyanti31@ui.ac.id \\ Universitas Indonesia Jakarta
}

\begin{abstract}
Germany nowadays is known as one of the most robust economies in Europe. Yet, at the beginning of 20th Century Germany, poverty became a severe problem that caused a social and cultural impact on the children. Positive selfesteem and resiliency in children were needed to cope with the situation. The roman titled Pünktchen und Anton, written in 1931 by Erich Kästner, describes the children's life in Berlin dealt with the poverty problem. This research aims to see how self-esteem and resiliency in children described as a life tool for the first figure (Anton) who classified as an adversity child in the novel. This question is answered by using descriptive qualitative method and self-esteem theory by Nathaniel Branden. The result shows there is advocacy in describing a marginalized Anton to become a hero thank to his positive self-esteem (selfefficacy and self-respect). His positive self-esteem builts him to be resilient.
\end{abstract}

Keywords: Püntchen und Anton, marginalized child, self-efficacy; self-esteem; self-respect

\section{PENDAhUluAN}

Fenomena anak marginal tidak hanya terjadi di negara berkembang seperti Indonesia, tetapi juga terjadi di salah satu negara yang memiliki kekuatan ekonomi terbaik di Eropa, yaitu Jerman.Menurut organisasi Terre des Hommes (TDH), terdapat ribuan anak yang bekerja di jalanan, khususnya di kota-kota besar seperti Hamburg dan Berlin. Adanya kesenjangan yang tumbuh antara kaya dan miskin menjadi salah satu faktor yang mendorong anak-anak di bawah 18 tahun untuk bekerja di jalanan (Deutsche Welle 2007). Selain itu, semenjak diterapkannya kebijakan pintu terbuka (open-door policy) oleh Kanselir Jerman Angela Merkel pada pertengahan tahun 2015, terdapat lebih dari satu juta pengungsi yang telah memasuki Jerman. Hal tersebut mengakibatkan terjadinya krisis pengungsi di Eropa khususnya Jerman, mengingat Jerman adalah salah satu negera di Eropa yang bersedia menampung pengungsi dalam jumlah besar. Meskipun para pengungsi telah mendapatkan berbagai bantuan termasuk tunjangan sejak kedatangannya di Jerman, mereka tetap harus mencari sumber pendapatan lain untuk tetap dapat bertahan hidup di Jerman. Para pengungsi mengalami kesulitan mendapatkan pekerjaan di Jerman sehingga banyak anak pengungsi yang memilih bekerja di jalanan untuk membantu keluarga mereka menyambung kehidupan (Hindy 2018). Anak marginal, termasuk anak-anak yang bekerja di jalanan dan anak-anak pengungsi, berisiko menjadi korban kekerasan bahkan korban perdagangan manusia. Pada awal tahun 2017, Kantor Investigasi Kriminal Federal Jerman (Bundeskriminalamt/BKA) mencatat lebih dari 8.400 anak pengungsi di bawah umur yang hilang. Sedangkan pada awal tahun 2019, jumlah tersebut menurun menjadi sekitar 3.200 anak. European Migration 
Network (EMN) memperingatkan adanya kemungkinan anak-anak tersebut menjadi korban kejahatan (Eisele 2019). Salah satu cara agar anak-anak dari risiko tersebut dan tetap dapat bertahan mengahadapi kondisi yang tidak menguntungkan (adversity), adalah dengan memiliki kemampuan resiliensi yang baik. Salah satu faktor penentu yang signifikan bagi kemampuan resiliensi pada anak adalah self-esteem.

Self-esteem dapat diartikan sebagai perasaan nyaman dan senang dengan diri sendiri. Informasi mengenai selfesteem pada masa kanak-kanak sangat diperlukan, karena masa ini adalah periode yang sangat penting untuk pengembangan self-esteem anak. Dalam buku The Power of Self-esteem, Branden $(1992,8)$ mendefinisikan self-esteem sebagai pengalaman bahwa seorang individu pantas untuk hidup di dunia ini. Secara spesifik, self-esteem adalah (1) rasa percaya diri pada kemampuan untuk berpikir dan menghadapi tantangan dasar kehidupan; (2) sebuah keyakinan di dalam individu bahwa dirinya pantas untuk bahagia, serta perasaan pantas untuk menikmati hasil dari upaya yang individu telah lakukan.

Memiliki self-esteem yang positif bukan berarti anak menjadi individu yang arogan atau egois, melainkan dapat menghargai dirinya sendiri, bertanggung jawab atas tindakannya, serta menunjukkan rasa hormat dan kepeduliannya terhadap orang lain. Anak-anak yang merasa nyaman dan senang dengan dirinya sendiri, memiliki kepercayaan diri untuk mencoba hal-hal baru tanpa adanya ketakutan bahwa mereka akan mengalami kegagalan, serta merasa bangga dengan apa yang mereka telah lakukan untuk dirinya sendiri atau orang-orang di sekitarnya. Ketika anakanak menghadapi kegagalan, mereka tidak akan cepat putus asa dan akan terus mencoba sampai akhirnya berhasil.
Self-esteem yang positif dapat mendukung stabilitas psikologis anak dan merupakan elemen yang penting untuk perkembangan psikologis anak (Wu et al. 2015, 880). Memiliki selfesteem yang positif sangat penting untuk membentuk anak menjadi individu yang positif, dan juga dapat membantu anak untuk mengembangkan kemampuan resiliensinya sehingga anak menjadi individu yang resilien dan dapat berhasil menghadapi kondisi yang tidak menguntungkan (adversity). Self-esteem dilihat sebagai karakteristik individu yang dapat bertahan dalam kesulitan bahkan berhasil mengatasinya.

Selanjutnya, Sondhi-Garg (2004) menjelaskan bahwa resiliensi adalah kapasitas individu untuk menghadapi peristiwa buruk, bertahan ketika menghadapi kesulitan yang cukup besar, dan tidak hanya mengatasinya, tetapi juga menjadi lebih kuat (Ali, 2011, 260).

Tema self-esteem dan kemampuan resiliensi ini dibahas dalam roman anak Pünktchen und Anton karya Erich Kästner yang diterbitkan pada tahun 1931. Hal yang menarik dari roman anak ini adalah sang penulis merangkum semua renungan ke dalam bab khusus yang terdapat di setiap akhir bab roman anak ini. Bagian renungan tersebut diberi judul: Renungan Nomor Sekian.

Roman anak Pünktchen und Anton ini memiliki latar waktu pada awal tahun 1930-an. Pada saat itu terjadi gangguan dan pergolakan besarbesaran di Jerman. Hal tersebut ditandai dengan perubahan rezim yang drastis, dan kemerosotan ekonomi. Kemerosotan ekonomi pada saat itu mengakibatkan jutaan orang kehilangan pekerjaannya (Evans 2018).

Secara keseluruhan, roman anak Pünktchen und Anton menceritakan tentang kehidupan dan persahabatan Pünktchen Pogge dan Anton Gast. Pünktchen, putri seorang direktur pabrik, berasal dari keluarga dengan 
status sosial ekonomi yang tinggi. Berbeda dengan Pünktchen, Anton berasal dari keluarga dengan status sosial ekonomi yang rendah. Persahabatan Pünktchen dan Anton dimulai di Jembatan Weidendammer di kota Berlin. Kegiatan Anton di jembatan tersebut adalah menjual tali sepatu, sedangkan Pünktchen berserta pengasuhnya, Fräulein Andacht, mengemis dan menjual korek api.

Hampir setiap malam, Fräulein Andacht menyelinap keluar rumah keluarga Pogge untuk mengajak Pünktchen pergi ke Jembatan Weidendammer. Pünktchen dengan senang hati ikut dengan Fräulein Andacht karena ia merasa kegiatannya di Jembatan Weidendammer itu sangat menyenangkan.

Konflik terjadi ketika pada suatu malam orang tua Pünktchen mengetahui bahwa hampir setiap malam Pünktchen berada di Jembatan Weidendammer bersama pengasuhnya. Di saat yang bersamaan, Anton berhasil menggagalkan perampokan di rumah keluarga Pogge yang dilakukan oleh tunangan Fräulein Andacht, dan tentu saja perampokan tersebut dibantu oleh Fräulein Andacht.

Seperti roman-roman anak pada umumnya, cerita dalam Pünktchen und Anton berakhir dengan bahagia. Secara keseluruhan, roman anak ini mengangkat permasalahan kehidupan anak-anak yang cukup kompleks, salah satunya adalah kemiskinan dan perbedaan status sosial. Roman anak ini memperlihatkan sisi lain dunia anak yang tidak hanya tentang keceriaan. Selain itu, roman anak Pünktchen und Anton (1931) juga menggambarkan tentang persahabatan, perbedaan status sosial ekonomi, dan kriminalitas yang terjadi di kota besar. Untuk dapat berhasil menghadapi sisi lain dunia anak tersebut, dibutuhkan kemampuan resiliensi yang baik pada tokoh di dalam roman anak ini.

Penelitian ini bukan penelitian pertama yang menggunakan roman anak Pünktchen und Anton sebagai korpus data utama. Penulis menemukan satu artikel jurnal yang telah menganalisis roman anak ini. Artikel tersebut berjudul Nilai Pendidikan Karakter dalam Novel Sastra Anak Pünktchen und Anton Karya Erich Kästner yang ditulis oleh Fierda Octiara Puteri pada tahun 2015. Permasalahan yang menjadi fokus utama artikel ini adalah mengenai nilai-nilai pendidikan karakter yang terkandung di roman anak Pünktchen und Anton. Puteri (2015) berpendapat bahwa di dalam roman anak ini terdapat hal-hal yang dianggap baik maupun buruk yang memuat nilai-nilai dalam mengembangkan karakter pembaca yang mayoritasnya adalah anak-anak. Fokus penelitian tersebut adalah nilai pendidikan karakter yang secara langsung disampaikan oleh tokoh Pünktchen dan Anton, melalui tingkah laku tokoh, baik secara verbal, fisik, pikiran dan perasaan, peristiwa, dan juga konflik yang dialami.

Selain itu, tema mengenai selfesteem juga merupakan tema yang sering diangkat, salah satunya dalam artikel yang berjudul Self-Esteem and Hopelessness, and Resiliency: An Exploratory Study of Adolescents in Turkey yang ditulis oleh Zeynep Karatas dan Firdevs Savi Cakar pada tahun 2011. Penelitian yang mendasari artikel ini merupakan penelitian kualitatif yang menggunakan 223 siswa Sekolah Menengah Atas di Turki sebahgai partisipan. Permasalahan yang diangkat dalam penelitian ini adalah self-esteem dan keputusasaan sebagai prediktor kemampuan resiliensi pada remaja. Hasil penelitiannya menunjukkan bahwa selfesteem dan keputusasaan adalah faktor penentu yang signifikan bagi kemampuan resiliensi pada remaja. Karatas \& Cakar (2011) berargumen bahwa terdapat hubungan positif antara self-esteem dan kemampuan resiliensi, tetapi di sisi lain terdapat hubungan negatif di antara keduanya. 
Ketika self-esteem seorang individu meningkat, maka kepercayaan dirinya juga meningkat. Selain itu, apabila selfesteem seseorang meningkat, kemampuan resiliensinya juga akan meningkat.

Berdasarkan latar belakang yang telah dipaparkan di atas, terlihat pentingnya self-esteem dan kemampuan resiliensi pada anak, yang antara lain dapat dituangkan melalui karya-karya sastra untuk anak.

Roman anak dapat memberi pengaruh dalam perkembangan perasaan hormat diri dan kemampuan resiliensi karena pembaca dapat mengidentifikasi diri dengan para tokoh dalam roman. Namun, penelitian mengenai hal itu belum banyak dilakukan.

Oleh karena itu, penelitian ini mengangkat persoalan tersebut sebagai fokus penelitian. Secara khusus, penelitian ini menganalisis self-esteem dan kemampuan resiliensi anak marginal dalam sastra, dengan menggunakan roman anak Pünktchen und Anton karya Erich Kästner sebagai korpus data. Penelitian ini bertujuan untuk mengungkap bagaimana selfesteem dapat mempengaruhi kemampuan resiliensi tokoh Anton dalam menghadapi kondisi tidak menguntungkan (adversity).

Penelitian ini adalah penelitian pustaka yang menggunakan pendekatan deskriptif-kualitatif. Penelitian kualitatif menurut Bogdan \& Taylor (dalam Moleong 2010: 4) adalah penelitian yang menghasilkan data berbentuk deskriptif berupa kata-kata tertulis atau lisan dari orang-orang dan perilaku yang dialami. Penulis menghimpun informasi-informasi yang relevan dengan topik penelitian yang diperoleh melalui buku, tesis, artikel online, dan jurnal.

Teori yang digunakan penulis untuk menganalisis self-esteem tokoh Anton dalam roman anak Pünktchen und Anton adalah teori self-esteem yang dikemukakan oleh Nathaniel Branden dalam bukunya yang berjudul The Six Pillars of Self-Esteem (1994). Menurut Branden (1994) terdapat dua komponen self-esteem, yaitu (1) self-efficacy (efikasi diri), yaitu keyakinan pada kemampuan individu untuk berpikir, belajar, memilih dan membuat keputusan yang tepat; dan (2) selfrespect (hormat diri), yaitu keyakinan pada cinta, persahabatan, prestasi, dan kesuksesan-dengan kata lain kebahagian-adalah hal yang wajar dan pantas. Dapat dikatakan bahwa selfefficacy dan self-respect merupakan dua pilar self-esteem yang positif. Apabila salah satu komponen tidak terpenuhi, maka self-esteem individu akan terganggu.

Selain itu, penulis juga menggunakan teori self-esteem lainnya dari Nathaniel Branden dalam bukunya yang berjudul Self-Esteem Everyday (1997) untuk menganalisis self-esteem dan kemampuan resiliensi tokoh Anton. Menurut Branden (1997):

Apabila individu memiliki self-esteem yang tinggi, individu tersebut mungkin masih akan merasakan tekanan emosional, tetapi hal ini lebih jarang terjadi dan pemulihannya akan lebih cepat karena kemampuan resiliensinya lebih baik.

\section{PengGambaran SELF-ESTEEM}

TOKOH ANTON MELALUi KONSEP

\section{SELF-EFFICACY DAN SELF-RESPECT}

Roman Pünktchen und Anton (1931) menceritakan petualangan dua sahabat, yakni Pünktchen dan Anton. Mereka berdua memiliki latar belakang keluarga dan sosial ekonomi yang sangat berbeda. Dalam roman ini, Anton digambarkan sebagai anak lakilaki teladan yang memiliki self-esteem yang positif meskipun ia hidup di dalam kondisi yang tidak menguntungkan (adversity).

Anton hanya tinggal bersama ibunya, Frau Gast, di sebuah bangunan yang sangat tua. Di sepanjang cerita tidak dijelaskan mengenai keberadaan seorang ayah di dalam kehidupan 
Anton. Kondisi yang tidak menguntungkan (adversity) yang dihadapi oleh keluarga single parent dengan anak tunggal adalah masalah finansial, terutama pada keluarga single parent dengan status sosial ekonomi yang rendah (Riyanda \& Soesilo 2018, 61). Permasalahan ini juga dihadapi oleh Frau Gast. Untuk menyambung kehidupan keluarga kecilnya, Frau Gast bekerja sebagai petugas pembersih gedung, tetapi ia tidak dapat bekerja selama beberapa minggu karena sedang sakit.

Selama Frau Gast beristirahat di rumah, seluruh pekerjaan rumah dikerjakan oleh Anton seorang. Pünktchen, sahabatnya, sempat menanyakan penyakit yang diderita oleh ibunya kepada Anton. Anton bercerita kepada Pünktchen bahwa ibunya sudah dua minggu dirawat di rumah sakit karena ada sesuatu yang tumbuh di dalam tubuhnya.

Setelah dua minggu di rumah sakit, keadaan Frau Gast jauh lebih membaik. Setiap hari Anton menjenguk untuk menghibur ibunya yang kesepian. Perawat-perawat di rumah sakit selalu bersikap ramah terhadap Anton, tetapi Anton merasa perawatperawat tersebut berpikir bahwa ibunya akan meninggal.

Setelah mendengarkan cerita Anton, Pünktchen berpendapat bahwa mungkin yang ada di dalam tubuh Frau Gast adalah tanaman dan pot yang tidak sengaja Frau Gast telan. Mendengar pendapat Pünktchen, Anton berkata: "Bukan. Bukan. Benda yang tumbuh itu terdiri atas kulit dan daging. Dan kalau tidak dikeluarkan, orang itu akan meninggal."

Memahami fakta-fakta dari sebuah kenyataan merupakan salah satu bentuk dari self-efficacy (Branden, 1994, 40). Meskipun Anton tidak mengetahui penyakit yang Frau Gast derita adalah kanker, namun Anton dapat menjelaskan kepada Pünktchen mengenai konsep penyakit kanker yang terdiri atas kulit dan daging yang tumbuh di dalam tubuh ibunya. Anton juga mengetahui bahwa penyakit yang diderita ibunya sangat berbahaya, dan dapat berakhir dengan kematian apabila tidak segera dioperasi. Berbeda dengan Anton, pemahaman Pünktchen terhadap sebuah kenyataan masih sangat kekanak-kanakan. Pünktchen masih mengasosiasikan sesuatu yang "tumbuh" di tubuh Frau Gast dengan pot tanaman yang juga tumbuh.

Persahabatan antara Pünktchen dan Anton dimulai di Jembatan Weidendammer di kota Berlin. Jembatan Weidendammer bukanlah tempat bermain Anton dan Pünktchen, melainkan tempat mereka bekerja. Anton berjualan tali sepatu, sedangkan Pünktchen berserta pengasuhnya, Fräulein Andacht, mengemis dan menjual korek api.

Hampir setiap malam, Fräulein Andacht menyelinap keluar rumah keluarga Pogge dan mengajak Pünktchen untuk pergi ke Jembatan Weidendammer. Meskipun sama-sama bekerja di Jembatan Weidendammer, mereka memiliki tujuan yang sangat berbeda. Fräulein Andacht memberikan seluruh hasil berjualan dan mengemisnya kepada tunangannya, sedangkan tujuan Pünktchen hanya untuk bermain-main saja di Jembatan Weidendammer. Sedangkan Anton berjualan tali sepatu Anton untuk membantu ibunya, yang sudah dua minggu tidak dapat mencari nafkah.

Tokoh Anton menurut UNICEF (2001, 89) dikategorikan sebagai childreen on street, yakni anak-anak yang bekerja atau mengemis untuk mencari nafkah di jalanan dan kembali ke rumah pada malam hari. Tujuan childreen on street adalah membantu perekonomian keluarganya.

Penelitian yang dilakukan oleh Ojanuga (dalam Aptekar, 1994, 208) mendukung pernyataan sebelumnya bahwa anak-anak bekerja di jalanan karena mereka berasal dari keluarga yang miskin dan membutuhkan uang yang mereka peroleh, 80\% anak-anak 
tersebut masih tinggal bersama keluarga mereka.

Pünktchen juga dapat dikategorikan sebagai children on street. Meskipun anak jalanan sering dikaitkan dengan latar belakang keluarga dari kelas sosial ekonomi yang rendah, tetapi harus ditekankan kembali bahwa semua anak dari berbagai kebangsaan, situasi keluarga, atau kelas sosial ekonomi apapun dapat berpotensi menjadi anak jalanan (West 2003, 2).

Pünktchen dan anjingnya, Pfike, untuk pertama kalinya mengunjungi rumah keluarga Gast untuk menjenguk Anton. Sesampainya mereka di rumah Anton, Anton menyapa Pünktchen dan Pfieke dengan gembira karena ia begitu senang rumahnya dikunjungi oleh sahabatnya. Anton berkata kepada Pünktchen: "Senang rasanya, kau mau juga sekali-sekali menjengukku."

Kebahagiaan yang Anton rasakan ini adalah apa yang Branden (1997) sebut dengan self-respect, yakni keyakinan pada persahabatan merupakan hal yang wajar dan pantas. Anton tidak merasa jengkel ketika sahabatnya berkunjung ke rumahnya tanpa memberitahu dirinya terlebih dahulu. Anton juga tidak merasa malu ketika Pünktchen mengetahui bahwa tempat tinggal Anton sangat berbeda dengan rumah keluarga Pogge yang besar dan mewah.

Saat itu, Anton mengenakan celemek karena ia sedang memasak kentang rebus asin dan telur dadar untuk makan siang ibunya. Anton tidak merasa malu ketika Pünktchen melihat dirinya sedang memasak dan mengenakan celemek, meskipun memasak biasanya diasosiasikan dengan pekerjaan anak perempuan. Di dalam bab renungan kedua, Erich Kästner berpendapat bahwa anak lakilaki pantas merasa bangga apabila mereka memasak agar ibunya bisa makan tepat waktu:

"Tapi jika kamu memasak agar ibumu yang sakit bisa makan tepat pada waktunya, kamu bisa merasa bangga dengan dirimu sendiri." (Kastner 1931, 797)

Memiliki keterampilan memasak merupakan kebanggaan tersendiri bagi anak, terutama anak laki-laki, karena mereka tidak harus bergantung dengan orang lain di rumahnya, terutama ibunya. Anton dan ibunya hanya tinggal berdua sehingga Anton tidak dapat bergantung kepada orang lain apabila ibunya tidak dapat memasak. Satu-satunya yang dapat diandalkan oleh Anton adalah dirinya sendiri. Pada umumnya, beban untuk memasak diletakkan pada sosok perempuan, meskipun sebenarnya memasak adalah kegiatan yang bebas nilai. Fungsi memasak adalah untuk bertahan hidup sehingga semua orang seharusnya dapat memasak. Tetapi dalam masyarakat, ada stereotipe masak adalah kegiatan domestik yang dilakukan oleh perempuan.

Dengan menampilkan tokoh Anton yang dapat memasak dan juga merasa bangga dengan kemampuannya, roman ini memperlihatkan bagaimana nilainilai dalam masyarakat dilekatkan pada suatu gender tertentu dan dinegasikan melalui tokoh Anton. Selain itu, Anton juga tahu betul apa yang harus ia lakukan di dapur, mulai dari takaran garam yang diperlukan hingga tingkat kematangan kentang rebusnya. Anak-anak yang memiliki self-efficacy, merasa percaya diri dan bangga dengan apa yang mereka telah kerjakan. Memasak merupakan salah satu sumber kebanggaan bagi anakanak yang dapat mengurus dirinya sendiri dan juga orang-orang di sekitarnya.

Such \& Walker (2004) menyarankan kepada para ibu, terutama ibu yang bekerja, untuk 'berbagi' beban pekerjaan rumah dengan anak-anak mereka untuk memberikan rasa tanggung jawab dan mengembangkan keterampilan anak.

Pada bagian lain cerita, Frau Gast menyantap hidangan yang disiapkan 
oleh Anton dengan lahap dan memuji masakan Anton yang sangat lezat. Sambil makan, Frau Gast bercerita kepada Pünktchen bahwa hari sebelumnya Anton berhasil membuat perkedel untuk dirinya. Anton berusaha menutupi wajahnya yang berseri-seri ketika mendengar pujian dari ibunya.

Anak-anak dengan self-esteem yang positif akan mengekspresikan dirinya dengan kenyamanan dalam memberi dan menerima pujian, apresiasi, dan ekspresi kasih sayang (Branden 1994, 41). Pujian yang dilontarkan Frau Gast kepada Anton merupakan salah satu bentuk ekspresi kasih sayang seorang ibu kepada anaknya. Anton tidak berusaha mencoba untuk mengelak pujian dari ibunya, dan juga tidak menyombongkan dirinya atas pencapaiannya. Frau Gast telah membantu pembentukan self-esteem Anton dengan cara memberikan pujian kepada anak laki-lakinya atas pencapaiannya dalam keterampilan memasaknya.

Selanjutnya, Branden menjelaskan bahwa keluarga dapat mendukung munculnya self-esteem yang positif dengan meyakinkan anak bahwa mereka percaya pada kemampuan dan kebaikan yang ada di dalam diri anak mereka.

Pada suatu ketika, setelah makan siang, Frau Gast menyuruh Anton untuk potong rambut dan bermaksud memberikan uang untuk ongkos potong rambut tersebut. Anton menuruti permintaan ibunya untuk potong rambut, tapi ia menolak uang yang hendak diberikan ibunya karena ia sudah punya uang sendiri. Anton menolak uang dari ibunya karena ia berusaha untuk menjadi anak yang mandiri dan tidak ingin membebani ibunya.

Kemandirian merupakan salah satu sikap dari individu yang memiliki selfefficacy (Branden, 1994, 40). Membangun kemandirian adalah bagian dari keterampilan sosial seorang individu yang memungkinkan anak merasa bahwa mereka memiliki kendali atas hidup mereka. Salah satu proses pendewasaan diri anak adalah melalui kemandirian (Bowlby 1956, 587).

Selanjutnya, Anton menjelaskan kepada ibunya bahwa uang yang ia miliki merupakan hasil dari ia bekerja membawa koper-koper milik para penumpang di stasiun. Anton memutuskan untuk berbohong kepada ibunya karena Anton tidak ingin ibunya tahu bahwa hampir setiap malam ia berjualan tali sepatu di Jembatan Weidendammer tanpa sepengatahuan ibunya.

Self-efficacy yang dimiliki anak akan membantu anak membuat keputusan yang menurut dirinya tepat (Branden, 1994, 26). Anton tahu betul, apabila ia jujur kepada Frau Gast mengenai pekerjaannya di Jembatan Weidendammer, ibunya akan sangat khawatir dan tidak akan mengizinkannya untuk melanjutkan pekerjaan tersebut. Dan apabila ia berhenti berjualan tali sepatu di Jembatan Weidendammer, ia tidak bisa lagi membantu untuk meringankan beban hidup ibunya. Meskipun demikian, hal tersebut tidak mengubah kenyataan bahwa Anton telah berbohong kepada ibunya.

Pada malam harinya di Jembatan Weidendammer, ada seorang pria paruh baya yang menghampiri Anton, dan berkata bahwa seharusnya pada jam ini Anton sudah berada di tempat tidur, bukan ada di sini. Anton menjawab berjualan jauh lebih menyenangkan dibandingkan dengan tidur. Pria paruh baya tersebut merasa tidak enak hati karena ia tidak bermaksud menyinggung perasaan Anton, lalu ia memberikan sekeping uang lima puluh Pfennig kepada Anton. Anton sangat senang dan mengucapkan terima kasih kepada lelaki paruh baya tersebut.

Individu yang memiliki self-respect cenderung akan memperlakukan orang lain dengan hormat (Branden, 1994, 
48). Ucapan 'terima kasih' yang Anton sampaikan kepada pria paruh baya tersebut merupakan sebuah bentuk penghormatan yang luar biasa karena Anton menunjukkan bahwa ia sangat menghargai apa yang pria paruh baya itu telah lakukan untuk dirinya.

Mengucapkan 'terima kasih' menunjukkan apresiasi, rasa bersyukur, dan yang terpenting adalah seseorang yang mengucapkan 'terima kasih' memiliki sikap positif yakni menghormati oang lain dan dirinya sendiri. Anak akan memahami perilaku hormat ini sebagai cara terbaik untuk berkomunikasi dengan orang lain.

Sesampainya Anton di rumah, ia segera memeriksa keadaan ibunya yang sudah terlelap. Setelah ia memastikan ibunya baik-baik saja, ia bergegas ke dapur untuk menyembunyikan kopernya agar tidak ketahuan oleh Frau Gast. Anton merasa sangat lelah dan benar-benar mengantuk, namun Anton tetap menyempatkan diri untuk mencatat pengeluaran dan pemasukan yang ia dapatkan malam ini di sebuah buku tulis khusus. Uang yang berhasil ia kumpulkan sampai malam ini berjumlah lima Mark enam puluh sen. Namun sayangnya, lima Mark ini akan diminta oleh pemilik rumah sebagai uang sewa. Anton sebenarnya sangat ingin membeli sosis, tetapi apa daya uangnya tidak mencukupi sehingga rencana Anton untuk membeli sosis terpaksa ditunda terlebih dahulu.

Anton menunda keinginannya untuk membeli makanan kesukaannya agar ia bisa memenuhi kebutuhan Anton dan Frau Gast yang lebih penting, yaitu tetap bisa tinggal bersama-sama di tempat tinggal yang nyaman dan aman. Ia tahu bahwa ia tidak selalu akan mendapatkan apa yang ia inginkan. Menahan keinginan merupakan keterampilan sangat penting untuk dimiliki anak, dengan demikian anak akan belajar untuk mengendalikan diri.

Meskipun bekerja sampai larut malam, Anton sudah mengerjakan PR berhitungnya dan ia juga sudah mempersiapkan diri untuk ulangan mengeja besok. Self-efficacy membuat individu semakin sadar akan tanggung jawab atas pilihan yang individu buat (Branden, 1994, 39).

Anton telah membuat keputusan untuk berjualan tali sepatu di Jembatan Weidendammer hingga larut malam untuk membantu menghidupi dirinya dan ibunya. Namun ia tetap bertanggung jawab atas keputusan yang telah ia buat, yaitu tidak mengabaikan pendidikannya untuk mencapai tujuannya sebagai individu yang sukses.

Selanjutnya, Branden menjelaskan lebih lanjut bahwa dasar dari self-efficacy adalah kepercayaan dalam kemampuan untuk mempelajari apa yang perlu individu pelajari dan melakukan apa yang perlu individu lakukan untuk mencapai tujuannya.

Selain itu, self-respect yang dimiiki Anton membuat dirinya merasa bahwa ia berhak menjadi individu yang sukses dan bahagia. Ketika keluarga dari sosial ekonomi yang rendah menunjukkan tingkat kehangatan dan kohesi yang tinggi, anak-anak dapat jauh lebih berprestasi, dan keinginan untuk melanjutkan pendidikannya lebih tinggi agar dapat keluar dari siklus kemiskinan dan meningkatkan peluang hidup mereka (Benzies \& Mychasiuk 2009, 107).

Sepulang sekolah, Anton sangat terkejut melihat ibunya sudah bisa bangun dari tempat tidur. Ia melompat dengan gembira, lalu memeluk ibunya dengan erat. Anton sangat bersyukur ibunya sudah sembuh lagi.

Self-esteem yang positif terwujud dalam kenyamanan individu dalam mengekspresikan kasih sayang (Branden, 1992, 44). Salah satu cara paling kuat yang dapat dilakukan orang tua dan anak untuk menyampaikan rasa kasih sayang mereka adalah melalui sentuhan. 
Self-respect yang dimiliki Anton membuat dirinya merasa pantas untuk bahagia, serta pantas untuk dicintai dan mencintai (Branden 1992, 9). Anton juga merasa sangat gembira karena ibunya sudah memasak kacang merah dan sosis untuk makan siang mereka berdua. Ternyata Anton hanya perlu sedikit bersabar untuk mendapatkan apa yang ia inginkan.

Pada suatu malam, Anton kurang beruntung karena sedang hujan, dan ia kebagian di sisi jembatan yang sepi. Mendadak Anton tersentak kaget ketika ia melihat Robert, tunangan Fräulein Andacht, yang sedang berjalan menghampiri Fräulein Andacht. Selfefficacy yang dimiliki Anton membantu dirinya untuk berpikir dan memahami apa yang sebenarnya sedang terjadi. Self-efficacy berarti keyakinan pada berfungsinya pikiran individu, kemampuan untuk berpikir, memahami dan membuat keputusan (Branden, 1994, 26).

Anton sangat curiga ketika melihat Robert berada di Jembatan Weidendammer. Kecurigaan Anton terhadap Robert semakin bertambah ketika ia melihat Fräulein Andacht memberikan satu rangkaian kunci kepada Robert dan lembaran kertas. Anton sangat yakin bahwa kunci yang diberikan kepada Robert adalah kunci rumah keluarga Pogge, dan kertas yang dipegang oleh Robert tersebut adalah denah yang Pünktchen ceritakan.

Pünktchen sempat bercerita kepada Anton bahwa Fräulein Andacht menggambar beberapa gambar berbentuk kotak di lembaran kertas. Salah satunya diberi keterangan 'Ruang Duduk' dan ada juga yang diberi keterangan 'Kamar Kerja'. Pünktchen tidak mengerti apa yang dikerjakan Fräulein Andacht saat itu. Setelah mendengarkan penjelasan dari Pünktchen, Anton tahu betul bahwa yang digambar oleh Fräulein Andacht adalah denah rumah keluarga Pogge.

Anton segera membuat keputusan untuk memberitahu keluarga Pogge mengenai perampokan yang akan dilakukan Robert. Self-respect yang dimiliki Anton membuat dirinya merasa nyaman untuk menyatakan apa yang ada di pikirannya (Branden, 1994, 26).

Tanpa pikir panjang Anton langsung berjalan menuju restoran terdekat untuk meminjam buku telepon, lalu mencari halaman huruf 'P'. Setelah mendapatkan nomor telepon rumah keluarga Pogge, ia bergegas ke telepon umum. Ternyata Berta, pembantu rumah tangga keluarga Pogge, yang mengangkat telepon dari Anton. Anton memberi tahu Berta bahwa sebentar lagi tunangan Fräulein Andacht akan tiba di rumah keluarga Pogge. Tunangan Fräulein datang untuk merampok, dan ia sudah memegang kunci pintu depan serta denah rumah keluarga Pogge. Anton menyarankan Berta untuk segera menelepon polisi, dan apabila tunangan Fräulein Andacht datang, hajar kepalanya dengan keras. Sekali lagi Anton mengingatkan Berta untuk menelepon polisi, lalu ia menutup teleponnya.

Berta melakukan apa yang Anton perintahkan kepada dirinya. Tidak lama kemudian polisi datang dan menangkap tunangan Fräulein Andacht. Polisi mengamankan denah beserta kunci rumah keluarga Pogge dan sebuah pistol. Pada malam itu Anton telah berhasil menggagalkan perampokan di rumah keluarga Pogge berkat self-efficacy dan self-respect yang ada di dalam dirinya.

Pada malam yang sama, Herr Pogge akhirnya mengetahui bahwa hampir setiap malam Pünktchen pergi bersama Fräulein Andacht ke Jembatan Weidendammer. Herr Pogge mengajak Frau Pogge untuk melihat Pünktchen dan Fräulein Andacht yang sedang mengemis di jembatan tersebut. Frau Pogge sangat terkejut dan merasa sangat sedih melihat anak semata wayangnya sedang mengemis-ngemis. Lalu Herr Pogge meminta polisi untuk 
menangkap Fräulein Andacht yang telah mempekerjakan putrinya.

Kemudian, Anton menghampiri Pünktchen yang terlihat sangat cemas, lalu Anton bertanya apa yang sedang terjadi. Pünktchen bercerita bahwa ia ketahuan orang tuanya. Frau Pogge melihat Pünktchen berbicara dengan Anton dan langsung memarahi Pünktchen karena mengobrol dengan anak gelandangan. Anton sangat tidak terima dengan perkataan Frau Pogge yang tidak beralasan. Meskipun demikian, Anton tetap akan menghormati Frau Pogge karena ia adalah ibu dari sahabatnya:

"Asal Anda tahu saja, saya sama baiknya dengan Anda sejak lama. Dan kalau saja Anda bukan ibu dari sahabat saya ini, maka saya takkan mau berbicara dengan Anda lagi, mengerti?" (Kastner 1931, 902)

Semakin tinggi self-esteem seorang individu, maka individu tersebut akan memperlakukan orang lain dengan rasa hormat, kebajikan, niat yang baik, dan adil (Branden, 1994, 7). Maka dari itu, meskipun Frau Pogge telah menghina Anton dengan sebutan 'anak gelandangan', Anton tetap akan menghormatinya karena ia adalah ibu dari sahabatnya.

Self-respect yang dimiliki Anton merupakan sebuah keyakinan bahwa dirinya pantas untuk dihormati oleh orang lain. Apabila individu menghormati dirinya sendiri, individu tersebut lebih cenderung untuk menegaskan dan memperkuat selfrespect yang dimiliki, seperti mengharuskan orang lain untuk memperlakukan dirinya dengan pantas (Branden, 1994, 39).

Keesokan harinya, sepulang dari sekolah, Pünktchen begitu bahagia karena dijemput oleh Herr Pogge. Akhirnya Herr Pogge memiliki waktu untuk menjemput anak perempuannya. Herr Pogge juga ingin menjemput Anton dari sekolah untuk makan kue sus bersama di Charlottenhof. Anton nyaris pingsan ketika melihat
Pünktchen dan Herr Pogge menunggu dirinya di mobil mewah milik Herr Pogge. Selama perjalanan, Herr Pogge memuji keberanian serta kecerdikan Anton. Anton hanya menjawab bahwa memang sudah seharusnya ia bertindak seperti itu. Menurut Branden (1994), seorang anak yang menerima respect dari orang dewasa cenderung mendorong self-respect mereka.

Selanjutnya, Pünktchen bercerita kepada Herr Pogge tentang Anton yang bisa melakukan banyak hal dengan bangga. Anton pantas merasa bangga dengan keberaniannya menggagalkan pencurian di rumah keluarga Pogge dan kemampuan lainnya yang ia miliki, namun ia tidak merasa sombong atas tindakannya tersebut. Kebanggaan menurut Branden (1994) lebih berkaitan dengan kesenangan yang secara eksplisit dirasakan oleh individu atas tindakan dan pencapaian individu. Kebanggaan yang otentik tidak memiliki kesamaan dengan menyombongkan diri dan arogansi seorang individu.

Terdapat miskonsepsi bahwa anak yang berasal dari keluarga dengan status sosial ekonomi yang tinggi pasti memiliki self-esteem yang positif (Dayton 2011). Namun,tidak selamanya demikian. Salah satu faktor yang memengaruhi perkembangan selfesteem anak adalah lingkungan keluarga.

Di dalam roman anak ini, meskipun berasal dari keluarga yang tidak utuh dengan status sosial ekonomi yang rendah, Anton memiliki hubungan yang erat dengan ibunya. Hubungan erat antara Anton dan ibunya mendorong perkembangan self-esteem yang positif untuk Anton. Ibu Anton selalu berusaha untuk membantu perkembangan self-esteem anaknya dengan cara memberikan perhatian yang cukup.

Selain itu, ibu Anton selalu meyakinkan Anton bahwa ia percaya dengan kemampuan dan kebaikan yang ada di dalam diri Anton. Meskipun 
hidup di dalam keterbatasan dan kesederhanaan, ibu Anton telah menciptakan lingkungan yang membuat Anton merasa aman dan nyaman.

Di sisi lain, tokoh Pünktchen berasal dari keluarga dengan status sosial ekonomi yang tinggi. Berbeda dengan Anton, Pünktchen tidak memiliki hubungan yang hangat dengan kedua orang tuanya.

Ayah Pünktchen, yang merupakan seorang direktur di sebuah pabrik, sudah terlalu sibuk dengan pekerjannya. Sedangkan, ibu Pünktchen tidak memiliki pekerjaan namun ibu Pünktchen terlalu sibuk dengan kehidupan sosialnya sehingga ia tidak memiliki waktu untuk mengasuh Pünktchen. Pünktchen sejak masih sangat kecil sudah diasuh oleh seorang pengasuh. Perhatian dari orang dewasa yang Pünktchen dapatkan hanyalah dari pengasuhnya dan orangorang yang bekerja di rumah keluarga Pogge. Dapat dikatakan bahwa keluarga Pünktchen adalah keluarga yang disfungsional.

Akhirnya Pünktchen mencari seseorang untuk bermain dengan dirinya di luar rumah tanpa sepengetahuan orang tuanya. Kurangnya perhatian dan waktu kebersamaan, membuat Pünktchen merasa bahwa dirinya tidak cukup untuk kedua orang tuanya. Hal tersebut merupakan faktor penghambat perkembangan self-esteem anak yang positif.

KEMAMPUAN RESILIENSI TOKOH ANTON SEBAGAI ANAK DENGAN SELF-ESTEEM Positif

Self-esteem positif yang dimiliki oleh Anton membantu Anton untuk membangun kemampuan resiliensinya, dan menjadikan Anton sebagai anak yang resilien.

Menurut Jindal-Snape dan Miller (2008), anak yang memiliki self-esteem yang tinggi akan lebih resilien ketika dihadapkan dengan tantangan. Anak- anak yang berhasil menghadapi tantangan cenderung memiliki selfesteem yang tinggi.

$\begin{array}{ccr}\text { Apabila } & \text { self-esteem } & \text { rendah, } \\ \text { kemampuan } & \text { resiliensi } & \text { dalam }\end{array}$ menghadapi kesulitan hidup akan berkurang. Self-esteem mengekspresikan dirinya dalam fleksibilitas individu dalam menghadapi suatu situasi dan tantangan karena individu mempercayai pikirannya, dan tidak memandang hidup sebagai malapetaka dan kekalahan (Branden 1994, 18).

Meskipun memiliki self-esteem yang positif, Anton masih tetap merasakan tekanan emosional. Anton tidak memiliki bakat berdagang dan ia tidak tahu bagaimana caranya untuk merengek-rengek agar dagangannya laku. Sebenarnya dalam hati Anton ingin menangis, namun ia tidak menunjukkan kesedihannya kepada orang lain:

"Ia tidak memiliki bakat berdagang. Ia tidak tahu bagaimana caranya untuk merengek kepada orang-orang, meskipun ia lebih ingin menangis dibandingkan dengan tertawa." (Kastnet 1931, 831)

Anton berhasil mengontrol emosinya dengan baik dalam menghadapi keadaan yang sulit seperti ini. Anak dengan kemampuan resiliensi yang baik akan mampu untuk bertahan dibawah tekanan emosional seperti kesedihan, dan tidak menunjukkan suasana hatinya yang negatif terusmenerus.

Anton tidak putus asa dan tetap berjualan, meskipun ia tidak memiliki bakat berdagang dan berada di sisi Jembatan Weidendammer yang jarang dilewati orang, karena ia ingin tetap dapat membantu ibunya secara finansial. Apabila ia berhenti bekerja, Anton tidak lagi bisa memberikan tempat tinggal yang nyaman dan aman untuk ibunya. Anton telah berjanji kepada pemilik rumah mereka bahwa ia akan mencicil uang sewa rumah sebesar lima Mark. Selain itu, uang 
belanja untuk sehari-hari juga sudah mulai menipis.

Ketika dioperasi, Frau Gast bertekad dalam hati untuk harus tetap hidup agar selalu bisa bersama Anton yang malang. Apabila ia tidak berjuang melawan penyakit yang ia derita, Anton akan berjuang sendirian karena Anton tidak memiliki siapa-siapa lagi selain dirinya. Dalam beberapa minggu terakhir ini, Anton telah melewati masa yang sangat sulit. Setiap hari Anton menjenguk ke rumah sakit, terpaksa makan di dapur umum, dan siang dan malam ia seorang diri di rumah. Setelah Frau Gast diizinkan pulang, ia harus berbaring di tempat tidur selama empat belas hari. Anton yang harus memasak dan belanja, dan beberapa kali ia bahkan mengepel lantai.

Satu hal yang tidak diketahui Frau Gast adalah Anton juga harus bekerja membanting tulang agar tetap bisa menghidupi dirinya dan juga ibunya. Anton benar-benar menyayangi ibunya, dan karena itu ia rela membanting tulang untuk membantu ibunya.

"Selama beberapa minggu terakhir ini, Frau Gast tidak bisa mencari uang. Padahal harus ada yang mencari uang. Anda tahu siapa yang mencari uang? Anton yang harus mencari uang!" (Kastner 1931, 850)

Kalimat-kalimat di atas merupakan penjelasan bagaimana untuk bisa tetap bertahan, Anton harus menjadi lebih dewasa dibandingkan dengan anakanak seumurannya. Selain itu, Anton harus bekerja lebih keras agar dapat bertahan dalam keadaan yang sulit.

$\begin{array}{llr}\text { Untuk } & \text { menghadapi } & \text { masalah } \\ \text { finansial } & \text { keluarganya, } & \text { Anton } \\ \text { melakukan } & \text { pemecahan } & \text { masalah }\end{array}$
(problem solving) atas masalahnya dengan cara berjualan tali sepatu di Jembatan Weidendammer. Anton memiliki keyakinan atas kemampuannya dalam menyelesaikan masalah yang ia hadapi.

Pada akhir cerita, Frau Gast bekerja sebagai pengasuh baru
Pünktchen atas permintaan Herr Pogge. Anton mengetahui berita tersebut ketika Herr Pogge memberitahu Pünktchen dan Anton bahwa mulai saat itu Frau Gast akan menempati kamar Fräulein Andacht dan Anton akan menempati kamar yang ada di sebelahnya.

Anton tidak sanggup berkata apaapa lagi ketika ia mendengar berita yang membahagiakan itu, kemudian ia menyalami Herr Pogge dan juga istrinya sebagai bentuk rasa terima kasih. Setelah itu, Anton mendekap ibunya dan berbisik bahwa mereka sekarang tidak perlu cemas lagi.

Self-esteem yang positif dan kemampuan resiliensi yang sangat baik membuat Anton memiliki sikap yang optimis terhadap perubahan yang terjadi di dalam kehidupannya dan juga ibunya di masa yang akan mendatang. Anton dapat secara efektif mengembangkan kemampuan resiliensinya karena ia mendapatkan dukungan emosional dari ibunya. Ketika keluarga menghadapi kesulitan secara bersama-sama, mereka lebih cenderung dapat mencapai tujuan mereka untuk keluar dari kesulitan tersebut. Selain itu, Anton juga mendapatkan dukungan sosial yang tinggi dari teman sebayanya dan orang lain di sekitarnya.

Menurut Grotberg (dalam Miller \& Daniel, 2007, 610), anak yang resilien cenderung mengatakan bahwa mereka memiliki orang yang mereka percaya dan cintai, dan mereka melihat dirinya sendiri sebagai individu yang dicintai.

Anton sangat yakin bahwa hidupnya akan menjadi lebih baik apabila ia terus berusaha dan tidak cepat putus asa. Keyakinan Anton bahwa hidupnya akan berubah menjadi lebih baik didukung oleh tindakan yang menunjukkan keinginannya untuk berubah. Selain itu, Anton dapat bangkit kembali setelah menghadapi masalah dan tidak mudah terpuruk ketika masalah datang menghampirinya. 
Mulai saat itu, Anton tidak perlu lagi berjualan tali sepatu di Jembatan Weidendammer untuk membayar sewa rumah dan memenuhi kebutuhan keluarganya sehari-hari. Anton bisa fokus melanjutkan pendidikannya agar keluarganya bisa keluar dari rantai kemiskinan.

\section{REALITAS KEHIDUPAN TOKOH ANTON SEBAGAi ANAK MARgINAL}

Semenjak Frau Gast terbaring sakit di tempat tidur setelah operasi, semua tugas Frau Gast dikerjakan oleh anak semata wayangnya. Setiap pulang sekolah, Anton mengerjakan pekerjaan rumah tangga yang tidak dikerjakan oleh anak-anak seumurannya, mulai dari mengepel lantai hingga memasak.

Tidak hanya itu, Anton diam-diam menjadi tulang punggung keluarganya. Dengan bermodalkan keberanian dan tekad yang besar, Anton memutuskan untuk berjualan tali sepatu di Jembatan Weidendammer pada malam hari tanpa sepengetahuan Frau Gast. Frau Gast hanya tahu bahwa Anton mendapatkan uang dari upah membantu membawa koper-koper para penumpang di stasiun.

Keadaan yang sulit tersebut menuntut Anton untuk menjadi lebih dewasa dibandingkan dengan anakanak lainnya. Anton harus mengesampingkan keinginannya untuk bermain dengan teman sebayanya, dan memberanikan diri untuk bekerja di jalanan. Banyak anak-anak, termasuk Anton, yang harus merelakan masa kecilnya untuk memperjuangkan kehidupan mereka di jalanan. Selain itu, tidak ada lagi yang dapat membantu ibunya selain Anton. Anton tidak memiliki ayah ataupun sanak keluarga lainnya yang dapat membantu dirinya.

Di Eropa, kemiskinan dan status sosial ekonomi yang rendah sering diasosiasikan dengan keluarga singleparent, terutama yang dikepalai oleh seorang wanita. Menurut penelitian yang dilakukan oleh Bertelsmann
Stiftung, hampir semua anak-anak dengan ibu yang bekerja baik penuh ataupun paruh waku, aman secara finansial. Namun ketika sang ibu berhenti bekerja untuk jangka waktu yang lama, hampir sepertiga anak-anak jatuh ke bawah garis kemiskinan.

Pekerjaan ibu memiliki pengaruh yang sangat kuat terhadap situasi kehidupan anak (Höppner 2018). Salah satu faktor yang dapat mencegah anakanak tumbuh di bawah garis kemiskinan adalah sang ibu bekerja setidaknya 30 jam dalam seminggu.

Bagi Frau Gast, hal tersebut hampir mustahil mengingat dirinya harus mengerjakan pekerjaan rumah tangga, dan juga mencari nafkah tanpa adanya bantuan dari pasangan. Selain itu, semenjak Frau Gast harus beristirahat di rumah, tidak ada lagi yang mencari nafkah. Akhirnya Anton, anak semata wayangnya, yang mengambil alih tanggung jawab Frau Gast.

Keberadaan Anton di jalanan membuat dirinya dipandang sebagai anak marginal, tanpa benar-benar mengetahui apa yang sebenarnya terjadi sehingga ia harus bekerja di jalanan. Terkadang keberadaan anak marginal dianggap sebagai sumber kriminalitas dan pengotor kota. Hal tersebut adalah stigma yang melekat pada anak marginal.

Anton juga dipandang sebelah mata oleh Frau Pogge, ibu Pünktchen. Tanpa mengetahui latar belakang kehidupan Anton, Frau Pogge memanggil Anton dengan sebutan 'anak gelandangan'. Selain itu, Frau Pogge juga tidak tahu bahwa tujuan Anton bekerja di jalanan adalah untuk menyambung kehidupan dirinya dan juga ibunya. Meskipun ia bekerja di jalanan, Anton tetap semangat melanjutkan pendidikannya agar ia bisa memutuskan rantai kemiskinan dan memiliki masa depan yang cerah.

Fenomena anak marginal tidak hanya terjadi di Jerman, tetapi juga terjadi di Indonesia, khususnya di kota Jakarta. Anak marginal menjadi 
fenomena yang tak terhindarkan sejak tahun 1990-an (Matsumoto 2006, 40). Mereka hampir selalu muncul di daerah yang sibuk seperti stasiun kereta api atau terminal bus, pasar tradisional, mal, dan persimpangan jalan yang padat.

Demartoto (dalam Bentley-Taylor, $2012,7)$ berpendapat bahwa anak-anak yang berasal dari keluarga miskin, berisiko lebih tinggi untuk bekerja di jalanan. Masalah kemiskinan di Indonesia menjadi alasan yang paling menonjol untuk mendorong anak berkerja di jalanan. Banyak keluarga hidup di dalam kemiskinan yang terjebak di dalam siklus pendidikan rendah, peluang kerja rendah, upah rendah, dan juga produktivitas rendah sehingga mengakibatkan anggota keluarga lainnya dibutuhkan untuk ikut berkontribusi dalam menghasilkan pendapatan untuk keluarga.

Selanjutnya penelitian yang dilakukan oleh Bentley-Taylor (2012) mengenai anak jalanan di Indonesia, menunjukkan bahwa dalam budaya Indonesia, anak yang lebih tua memiliki tanggung jawab yang signifikan untuk membantu orang tua mereka dengan mengorbankan kebutuhan dan keinginan mereka sendiri untuk memenuhi kebutuhan keluarganya. Harapan pada anak-anak yang lebih tua tersebut, terutama bagi mereka yang berasal dari keluarga sosial ekonomi yang rendah, mendorong anak untuk memilih bekerja di jalanan.

\section{KESIMPULAN}

Berdasarkan hasil analisis di terhadap tokoh Anton dalam roman anak Pünktchen und Anton, penulis menemukan bahwa kondisi yang tidak menguntungkan (adversity) bisa menjadi hal yang baik untuk perkembangan tokoh Anton. Kesulitan yang dihadapi tokoh Anton mendorong dirinya untuk tumbuh menjadi individu yang resilien. Self-esteem yang positif dan juga dukungan yang diterima tokoh Anton saat menghadapi berbagai kesulitan, membantu tokoh Anton untuk mengembangkan kemampuan resiliensinya. Selain itu, tidak dapat dipungkiri bahwa lingkungan keluarga, terutama orang tua, merupakan salah satu faktor vital yang memengaruhi perkembangan self-esteem tokoh Anton. Mengingat lingkungan keluarga merupakan lingkungan terdekat dengan anak dan lingkungan pertama yang anak kenal.

Self-esteem yang positif dan kemampuan resiliensi yang baik dapat menghindarkan tokoh Anton, yang notabene anak jalanan, dari risiko menjadi korban suatu tindak kejahatan di jalanan. Anak jalanan rentan menjadi korban kejahatan karena mereka menghabiskan waktu di jalanan tanpa adanya pengawasan dari orang dewasa. Kohesi antara self-esteem yang positif dan kemampuan resiliensi yang baik adalah alasan untuk memperkuat self-esteem anak.

\section{Daftar Pustaka}

Ali, Nelly. 2011. "The Vulnerability and Resilience of Street Children." Global Studies of Childhood, 1 (3): 260-264. <https://remotelib.ui.ac.id:2067/10.2304/ gsch.2011.1.3.260>

Aptekar, Lewis. 1994. "Street Children in the Developing World: A Review of Their Condition." Cross-Cultural Research $28 \quad$ (3): 195-224. $<$ https://doi.org/10.1177/1069397194028 00301>

Bentley-Taylor, Brenden. 2012. Searching for New Life: How Children Enter and Exit the Street in Indonesia (Master Thesis) University of Victoria. $<$ https://dspace.library.uvic.ca/handle/18 28/5958>

Benzies, Karen \& Richelle Mychasiuk. 2009. "Fostering Family Resiliency: A Review of the Key Protective Factors." Child \& Family Social Work, 14, (1): 103-114. <https://doi.org/10.1111/j.13652206.2008.00586.x>

Bowlby, John. 1956. "The Growth of Independece in Young Child." Royal Society of Health Journal, 76: 587-591 
$<$ https://doi.org/10.1177/1466424055076 00912>

Branden, Nathaniel. 1992. The Power of Self-Esteem. Deerfield Beach: Health Communications

Branden, Nathaniel. 1994. The Six Pillars of Self-Esteem. New York: Bantam

Branden, Nathaniel. 1997. Self-Esteem Everyday. New York: Simon \& Schuster

Dayton, Tian. 2011. "Growing Up Rich: How it Shapes Identity," The Huffington Post, November 17. <https://www. huffpost.com/entry/growing-up-rich-how -it-sh_b_109076>

Deutsche Welle, 2007, January 5 "Street Children on the Rise in Germany, Aid Agency Warns". <https://p.dw.com/p/ 9ecp>

Eisele, Ines, 2019. “Germany's Thousands of 'Missing' Refugee Minors," Deutsche Welle, January 28. <https://p.dw.com/p/ 3CLB4>

Evans, Richard J. 2018. "A Community of Defeat," The Nation, October 29. <https: //www.thenation.com/article/a-communi ty-of-defeat/>

Hindy, L. 2018. “Germany's Syrian Refugee Integration Experiment." The Century Foundation, September 10. $<$ https://tcf.org/content/report/germanys -syrian-refugee-integrationexperiment/?session $=1>$

Jindal-Snape, Divya \& D. Miller. 2008. “A Challenge of Living? Understanding the Psycho-Social Process of the Child During Primary-Secondary Transition Through Resilience and Self-Esteem Theories." Educational Psychology Review 20 (3): 217-236 <http://remotelib.ui.ac.id:2093/stable/23363889>

Karatas, Zeynep, \& Firdevs Savi Cakar. 2011. "Self-Esteem and Hopelessness, and Resiliency: An Exploratory Study of Adolescents in Turkey." International Education Studies 4 (4). doi:10.5539/ies. $\mathrm{v} 4 \mathrm{n} 4 \mathrm{p} 84$
Miller, David \& Brigid Daniel. 2007. "Competent to Cope, Worthy of Happiness?: How the Duality of SelfEsteem Can Inform a Resilience-Based Classroom Environment." School Psychology International 28 (5): 605622. doi:10.1177/0143034307085661

Moleong, Lexy J. 2010. Metodologi Penelitian Kualitatif. Bandung, Indonesia: Remaja Rosda Karya

Puteri, Fierda Octiara. 2015. "Nilai Pendidikan Karakter dalam Novel Sastra Anak Pünktchen und Anton Karya Erich Kästner." Identitaet 4 (2): 1-5. http://jurnalmahasiswa.unesa.ac.id/ index.php/identitaet/article/view/12273.

Riyanda, Wahyu Dhyanita Abhisekha Puspa \& Aloysius Soesilo. 2018. "Resiliensi Anak Tunggal yang Memiliki Orangtua Tunggal dengan Status Sosial Ekonomi Rendah." Psycho Idea, 16 (1): 59-73. doi:10.30595/ psychoidea.v16i1.2498

Such, Elizabeth, \& Robert Walker. 2004. "Being Responsible and Responsible Beings: Children Understanding of Responsibility." Children \& Society, 18, (3): 231-242. doi:10.1002/chi.795

UNICEF . 2001. A Study on Street Children in Zimbabwe. <https://www.unicef.org/ evaldatabase/index_14411.html>

West, Andrew. 2003. "At the Margins: Street Children in Asia and the Pacific." Poverty and Social Development, 8: 166. <http://hdl.handle.net/11540/2287>

Wu, Yie-Len, Jian Chen, Lin-Shen Yang, Xiu-Xiu Ding, Hui-Yun Yang, \& YeHuan Sun. 2015. "Change an Associated Factors of Self-Esteem among Children in Rural China: A Two-Year Longitudinal Study." Psychology, Health \& Medicine 20 (8): 879-888. doi:10. 1080/13548506.2014.983136 
170 Leksema Vol 4 No 2 Juli-Desember 2019 